\title{
Development of a Method for the Microwave-assisted Digestion of Soils Using Dilute Acids and the Simultaneous Determination of 18 Trace Elements by Inductively Coupled Plasma Mass Spectrometry
}

\author{
Krishnan Chandrasekaran ${ }^{\mathrm{a}, *}$, Puttam Reddy Mamatha ${ }^{\mathrm{b}}$, and Dheram Karunasagar ${ }^{\mathrm{a}}$ \\ a National Centre for Compositional Characterization of Materials (C.C.C.M.), \\ Bhabha Atomic Research Centre, Department of Atomic Energy, \\ E.C.I.L. Post, Hyderabad-500062, Telangana, India \\ b Jawaharlal Nehru Technological University Ananthapuram, College of Engineering, \\ Pulivendula-516 390, Kadapa, Andhra Pradesh, India
}

\begin{abstract}
A simple two-step microwaveassisted digestion process employing dilute acids was developed for the simultaneous determination of 18 elements ( $\mathrm{Li}, \mathrm{Be}$, $\mathrm{V}, \mathrm{Cr}, \mathrm{Co}, \mathrm{Ni}, \mathrm{Cu}, \mathrm{Zn}, \mathrm{Ga}, \mathrm{As}, \mathrm{Sr}$, $\mathrm{Mo}, \mathrm{Sn}, \mathrm{Ba}, \mathrm{Tl}, \mathrm{Pb}, \mathrm{Bi}$, and $\mathrm{U}$ ) in soil by inductively coupled plasma mass spectrometry. The soil sample $(\sim 0.3 \mathrm{~g})$ was initially digested using a mixture of $10 \%$ (v/v) $\mathrm{HNO}_{3}+7 \%$ (v/v) HF. Subsequently, the HF was removed by evaporation, and the final solution made into a dilute $\mathrm{HNO}_{3}+$ $\mathrm{HCl}$ mixture to prevent the elements from hydrolyzing. The goal was to develop a digestion method for monitoring the heavy metal content in soil samples, especially with a view to reduce the acid content and to enable the sample digests to be analyzed by inductively coupled plasma
\end{abstract}

techniques. The proposed method was validated by digesting and analyzing a certified soil reference material GBW-07409. The percentage recovery of the above trace elements varied from 86$107 \%$. Detection limits ranging from 0.001 to $0.04 \mathrm{mg} \mathrm{kg}^{-1}$ and relative standard deviation values lower than $10 \%$ were obtained. A standard digestion (total) procedure for soil analysis based on the USEPA 3052 method was applied and the results compared with those obtained by the developed method. Later, a sample of soil collected from Tummalapalle, Andhra Pradesh, India, where recently large uranium deposits have been identified and mining commenced, was analyzed, and the results are presented.

\section{INTRODUCTION}

Accumulation of metal contaminants in the environment is growing due to increased anthropological activities causing ecological concerns. Intense cultivation and open cast mining can lead to severe heavy metal pollution of soils. Pyrite, the most abundant sulphide found in metallic mine spoils, oxi-

\footnotetext{
*Corresponding author.

E-mail: kchandru73@rediffmail.com

Tel: 91-40-27121365

Fax: 91-40-27125463;
}

dizes to sulphate, leading to formation of sulphuric acid, thus causing acidic mine drainage that may solubilize other sulphates and trace metals (1). The resulting drainage and the solubilization of heavy metals can contaminate surface and underground waters by leaching (2).

Many studies are regularly carried out with a focus on heavy metals due to their potential risks to human health, distribution in the soil, mobility and availability to the soil biota. With an increasing understanding of their effects, countries have introduced guideline values relating to the maximum levels of contaminants that may be released into or contained in the environment. Threshold levels have been prescribed particularly to soils and groundwaters as metals in soils at even slightly elevated concentration levels, whether due to natural or anthropogenic factors, can result in their entry into the food chain, thus leading to serious consequences and subsequent health problems $(3,4)$.

Although trace elements $(\mathrm{Cu}, \mathrm{Fe}$, $\mathrm{Mn}, \mathrm{Ni}$, and $\mathrm{Zn}$ ) are essential plant micronutrients, elevated levels of metals in soil may lead to increased uptake by plants and affect the quality of agricultural products. Lead $(\mathrm{Pb})$ is nonessential and may exhibit extreme toxicity even at low levels. For these reasons, the monitoring of trace metals in agricultural soils is essential $(5,6)$.

The presence of any element in high concentration in the soil could be due to both natural and/or anthropogenic factors; it is often quite difficult to discriminate among the different causes. The parent material largely influences heavy metal content in many soil types, with concentrations sometimes exceeding the critical values $(7,8)$. Anthropogenic sources of heavy metal content in soils result mainly due to activities such as waste disposal and combustion processes in industry and transportation; mining activities for extrac- 
tion and manufacturing of metal products also result in a large amount of pollutants being released into the atmosphere and transported to the adjoining soil and waters. Long-term and intensive cultivation of agricultural land with the application of fertilizers and pesticides also results in accumulation of metals such as copper, nickel, zinc, and cadmium in the top soil (9). Soil pollution assessment becomes very complex, especially when different sources of contamination are present and their products are variably distributed. In these cases, the spatial variability of metal concentrations in soils is necessary for identifying the possible sources of contamination and to arrive at suitable strategies for soil remediation.

The low levels at which trace metals are present and are required to be determined mean that sensitive and selective methods of analysis need to be employed. Highly sensitive analytical techniques such as ICP-AES and ICP-MS often require the samples to be brought into a suitable liquid form prior to their analysis. Soils and sediments prove difficult to digest due to the presence of refractory phases and silicates. Their varied nature and differences in mineralogy from place to place make a single universal method impossible. The need to separate the anthropogenic contributions from native metal contents has led to the development of several sequential extraction schemes (10-14). The results obtained by these methods of extraction are often limited in their applicability to the determination of extractable elements using the given procedure. The lack of uniformity among these different schemes also does not allow easy comparability or validation. Therefore, the analytical results are often directly associated with the extraction scheme employed in the particular case.
Though sequential extraction procedures can provide estimates of potentially available metals and distinguish between those bound in the lattice structure of detrital minerals, the so-called residual fraction, they suffer from certain disadvantages such as limited efficiency and phase selectivity, re-adsorption during extraction, and are often laborintensive (15). In comparison, total digestion methods enable arriving at the anthropogenic contamination levels with good accuracy. However, in these cases it is necessary to obtain pristine, uncontaminated samples of the material under consideration. Wherever such samples are at hand, total digestion yields better estimates of man-made pollution. The determination of the total content of heavy metals in soils and sediments is particularly useful to collect information on the genesis of the soil and on the level of contamination.

The total digestion methods, with conventional digestion procedures such as the use of fluxes or inorganic acids, i.e., $\mathrm{HCl}, \mathrm{H}_{3} \mathrm{PO}_{4}$, $\mathrm{HNO}_{3}, \mathrm{HClO}_{4}, \mathrm{HF}, \mathrm{H}_{2} \mathrm{SO}_{4}$ or their combinations, are labor-intensive and tedious, and often may result in contamination. The more modern methods used are microwaveassisted digestion/ leaching $(16,17)$ and ultrasound-assisted leaching (18). These methods greatly reduce the analysis time, their 'closed operation' can minimize or eliminate contamination, prevent loss of volatile species (i.e., Se, As, and $\mathrm{Hg}$ ), use lower sample size and less reagent, and aid in operator safety. Additional benefits include the ability to deal with complex matrices such as soils, sludges, and sediments that do not easily lend themselves to dissolution. Laboratory microwave ovens with pressure and temperature control also tend to yield more controlled and reproducible results than the conventional methods (19). A large number of these extraction proce-

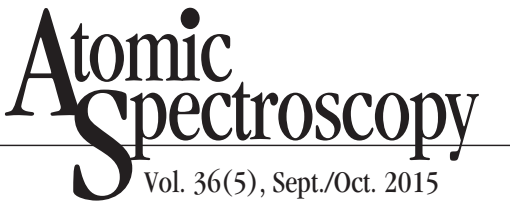

dures have often concentrated on the determination of six elements: $\mathrm{Cd}, \mathrm{Cr}, \mathrm{Cu}, \mathrm{Ni}, \mathrm{Pb}$, and $\mathrm{Zn}$.

Since its introduction, ICP-MS has proven to be the best multi-elemental analytical technique for the sensitive and rapid determination of trace metals. However, the presence of high acid content and organic content in the samples poses problems causing plasma instability and even extinction. The choice of sample digestion may also be the main source of systematic error, since extraction from siliceous materials by aqua regia, as employed in ISO 11466 (International Organization for Standardization) (20), is always liable to be incomplete $(21,22)$.

In view of the matrix content of many environmental samples (soils, sediments, sludges), a total digestion scheme must include the use of hydrofluoric acid (HF) to completely release the trace elements included in the aluminosilicate phase (23-27). However, the use of HF leads to long and cumbersome schemes and requires specialized sample introduction equipment when ICP techniques are used. Dilution or complexation with boric acid are often employed to overcome the problem, but it can affect the sensitivity of the method (5).

In the present work, a simple method has been developed for the microwave-assisted digestion of soil samples limiting the concentrations of acids, $\mathrm{HNO}_{3}$ and $\mathrm{HF}$, and at the same time achieving quantitative recoveries for a large number of elements: $\mathrm{Li}, \mathrm{Be}, \mathrm{V}, \mathrm{Cr}, \mathrm{Co}, \mathrm{Ni}, \mathrm{Cu}$, $\mathrm{Zn}, \mathrm{Ga}$, As, Sr, Mo, Sn, Ba, Tl, Pb, $\mathrm{Bi}$, and $\mathrm{U}$. These elements are of biogeochemical importance and were determined in the digests using an ICP-MS with good sensitivity and accuracy as demonstrated by analyzing the reference material. To our knowledge, this is the first time that dilute acids have been employed for total digestion of soil 
samples as opposed to selective leaching of the elements, resulting in quantitative recoveries for as many as 18 elements.

\section{EXPERIMENTAL}

\section{Instrumentation}

A VG Plasmaquad 3 inductively coupled plasma quadrupole mass spectrometer (ICP-QMS) (VG Elemental, Winsford, Cheshire, UK), situated in a class 100 laboratory, was used in this study. A Meinhard ${ }^{\circledR}$ concentric nebulizer was used for sample introduction through a water-cooled $\left(4^{\circ} \mathrm{C}\right)$ Scott-type double-pass spray chamber. The plasma operating conditions, such as the nebulizer flow rate, the position of the torch and RF power, and the ion lens voltages of the instrument, were optimized while continuously nebulizing a $10-\mu \mathrm{g} \mathrm{L}^{-1}$ multi-element standard solution of $\mathrm{Be}, \mathrm{Co}, \mathrm{Rh}, \mathrm{In}$, and $\mathrm{Bi}$ in $5 \% \mathrm{HNO}_{3}$ in order to maximize the ${ }^{103} \mathrm{Rh}^{+}$and ${ }^{115} \mathrm{In}^{+}$signals. The plasma operating conditions were selected to obtain high sensitivity across the mass range and low oxide levels. The reagents were introduced using a peristaltic pump (REGLO Digital MS-4/12, ISMATEC, Switzerland) at a flow

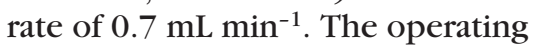
parameters of the ICP-QMS are listed in Table I. The soil samples were digested using a closed microwave digestion system (model MARS 5, CEM, USA) with PTFE vessels.

\section{Reagents and Solutions}

All chemicals were of analytical grade, unless stated otherwise. Sub-boiled $\mathrm{HNO}_{3}$ and $\mathrm{HCl}$ were prepared in-house in a class 10 clean bench, by sub-boiling in quartz stills using reagent-grade feedstock. Suprapur ${ }^{\circledR}$ grade HF (E-Merck, Darmstadt, Germany) was used in the digestion. Ultra-pure water with $>18.2 \mathrm{M} \Omega-\mathrm{cm}$ resistivity (Milli-Q ${ }^{\circledR}$ Element Water System, Millipore Corporation, Bedford, MA, USA) was used for dilution of the standards, preparing the samples, and final rinsing of the acid-cleaned vessels. All sample preparations were carried out on a class 10 clean bench. A multielement stock standard solution, ICP Multielement Standard Solution VI (Merck, Germany) containing 30 elements in $6 \%$ (v/v) $\mathrm{HNO}_{3}$ was used. Tin was added separately from a $1000-\mathrm{mg} \mathrm{L}^{-1}$ stock standard (Merck, Germany) during the preparation of a $1 \mathrm{mg} \mathrm{L}^{-1}$ intermediate multielement standard. Rhodium stock standard (1000 mg $\mathrm{L}^{-1}$ ) (Merck, Germany) was diluted and used as the internal standard. Calibration standard solutions in the range 2 - $20 \mu \mathrm{g} \mathrm{L}^{-1}$ were prepared in $2 \%(\mathrm{v} / \mathrm{v}) \mathrm{HNO}_{3}$ by diluting the multielement intermediate standard. A certified reference material (CRM) GBW 07409 Soil (National Research Centre for Certified Reference Materials, P.R. China) was used for validation of the method developed.

All laboratory ware was rinsed three times in ultrapure water after being soaked in $\mathrm{HNO}_{3}(10 \%$, v/v) bath overnight. Samples, reagents, and standards were prepared in a class 100 clean laboratory, containing a class 10 workbench with laminar airflow. The PTFE vessels used for microwave digestion were cleaned using $3 \mathrm{~mL}$ of sub-boiled $\mathrm{HNO}_{3}$ at high power (600W) for 20 minutes at $120^{\circ} \mathrm{C}$. The vessels were subsequently rinsed three times with ultrapure water .

\section{Soil Sampling}

The soil sample analyzed in this work was collected from an agricultural area in Tummalapalle village, located near the town of Pulivendula of the YSR Kadapa district, Andhra Pradesh state, India. This area contains uranium ore deposits associated with sedimentary formations, and uranium mining has been undertaken by UCIL (Uranium Corporation of India Limited), Department of Atomic Energy (DAE), India. The top $5 \mathrm{~cm}$ of detritus and soil was scraped off, and soil at a depth of $10-15 \mathrm{~cm}$ was collected with a corer. Subsamples from 30 locations of that area were gathered and mixed thoroughly to prepare a composite sample $(10 \mathrm{~kg})$. The composite sample was then powdered in a ball mill and sieved

TABLE I

Instrumental Conditions and Measurement Parameters for ICP-QMS

\begin{tabular}{ll} 
Model & VG Plasmaquad 3 \\
Rf forward power & $1350 \mathrm{~W}$ \\
Reflected power & $2 \mathrm{~W}$ \\
Coolant gas flow rate & $13.5 \mathrm{~L} \mathrm{~min}^{-1}$ \\
Auxillary gas flow rate & $0.9 \mathrm{~L} \mathrm{~min}-1$ \\
Nebulizer gas flow rate & $0.8 \mathrm{~L} \mathrm{~min}{ }^{-1} ;$ Optimized daily \\
Nebulizer & Meinhard ${ }^{\circledR}$ concentric \\
Spray chamber & Double pass Scott-type, water-cooled at $4^{\circ} \mathrm{C}$ \\
Ni Sampler cone orifice & $1.0 \mathrm{~mm} \mathrm{dia}$ \\
Ni Skimmer cone orifice & $0.7 \mathrm{~mm} \mathrm{dia}$ \\
Dwell time & $10 \mathrm{~ms}$ \\
Data acquisition mode & Peak Jump \\
Points per peak & 3 \\
Sample flow rate & $0.7 \mathrm{~mL} \mathrm{~min}{ }^{-1}$ \\
Element & ${ }^{7} \mathrm{Li},{ }^{9} \mathrm{Be},{ }^{51} \mathrm{~V},{ }^{52} \mathrm{Cr},{ }^{59} \mathrm{Co},{ }^{60} \mathrm{Ni},{ }^{63} \mathrm{Cu},{ }^{66} \mathrm{Zn},{ }^{71} \mathrm{Ga}$, \\
& ${ }^{208} \mathrm{~Pb},{ }^{838} \mathrm{Sr},{ }^{98} \mathrm{Mo},{ }^{115} \mathrm{In},{ }^{120} \mathrm{Sn},{ }^{137} \mathrm{Ba},{ }^{205} \mathrm{Tl}$, \\
\hline
\end{tabular}


through a 200-mesh sieve to get a fine powder of $<75 \mu \mathrm{m}$ size. The sieved samples were stored in dry polypropylene bottles.

\section{Microwave-assisted Digestion}

A sample $(\sim 0.3 \mathrm{~g})$ of the soil was weighed accurately into a wellcleaned PTFE digestion vessel, in triplicate. A mixture of $10 \%(\mathrm{v} / \mathrm{v})$ $\mathrm{HNO}_{3}+7 \%(\mathrm{v} / \mathrm{v}) \mathrm{HF}(10 \mathrm{~mL})$ was added and left standing at room temperature for 15 minutes for predigestion. Subsequently, the sample was introduced into the microwave digestion system and the program used is listed in Table II. After cooling, the digest was transferred into a 15-mL centrifuge vial and made up to a known volume and centrifuged at $5000 \mathrm{rpm}$. A suitable aliquot of the solution was taken into an acid-cleaned 7-mL PFA vial and evaporated over an IR lamp in a laminar flow clean bench to incipient dryness to remove excess HF. Care was taken to avoid heating beyond $90{ }^{\circ} \mathrm{C}$ to prevent any loss of solution by sputtering and/or splashing. When a few drops (100 $200 \mu \mathrm{L}$ ) of the solution were left, with traces of white residue at the bottom of the vial, $600 \mu \mathrm{L}$ of $\mathrm{HNO}_{3}$, $200 \mu \mathrm{L}$ of $\mathrm{HCl}$, and $1 \mathrm{~mL}$ of water were added and warmed for a few minutes until the residue dissolved completely. The solution was made up to a known volume with ultrapure water and stored at $4{ }^{\circ} \mathrm{C}$ until further analysis. A process blank was prepared simultaneously as above without the sample.

\section{USEPA 3052 Microwave Digestion Procedure}

US EPA 3052 is a standard method, applicable to the microwave-assisted acid digestion of siliceous matrices, organic matrices, and other complex matrices aimed at total decomposition (28). This method was employed for validation of the proposed new method. About $0.3 \mathrm{~g}$ of sample was digested using $9 \mathrm{~mL}$ of sub-boiled $\mathrm{HNO}_{3}$ and $4 \mathrm{~mL}$ of concentrated $\mathrm{HF}$; and the microwave program is listed in Table II.

TABLE II Microwave Digestion Program

\begin{tabular}{cccc}
\hline $\begin{array}{c}\text { Power } \\
(\mathrm{W})\end{array}$ & $\begin{array}{c}\text { Ramp } \\
(\mathrm{s})\end{array}$ & $\begin{array}{c}\text { Temp } \\
\left({ }^{\circ} \mathrm{C}\right)\end{array}$ & $\begin{array}{c}\text { Hold } \\
(\mathrm{min})\end{array}$ \\
\hline 600 & 5 & 100 & 10 \\
600 & 5 & 150 & 10 \\
600 & 5 & 200 & 10 \\
600 & - & 0 & 2 \\
600 & 2 & 220 & 5 \\
\hline
\end{tabular}

\section{ICP-MS Measurements}

Amounts of $1 \mathrm{~mL}$ and $0.2 \mathrm{~mL}$ of the sample digests were pipetted into two well-cleaned $15-\mathrm{mL}$ polypropylene (PP) centrifuge vials. Then, $0.1 \mathrm{~mL}$ of $1 \mathrm{mg} \mathrm{L}^{-1} \mathrm{Rh}$ was added as the internal standard to correct for any instrumental drift during the analysis. The solutions were then diluted to $10 \mathrm{~mL}$ with 2\% (v/v) $\mathrm{HNO}_{3}$, resulting in 10 and 50 times dilution, respectively. Two different dilutions were necessary to cover all of the 18 elements, as some of the elements are present at higher levels. The process blank solutions were diluted accordingly. For each solution, the entire mass range was scanned and data was acquired three times; the mean value of the signal was used for quantification. The above solutions were quantified by external calibration using multielement standards prepared in $2 \%(\mathrm{v} / \mathrm{v}) \mathrm{HNO}_{3}$ containing $10 \mu \mathrm{g} \mathrm{L}^{-1} \mathrm{Rh}$ as the internal standard. A multielement standard of known concentrations of the analytes was prepared separately as a quality control sample and after every three samples it was checked for instrument performance. The signal intensities obtained for the respective blanks were subtracted from the sample and the standard.

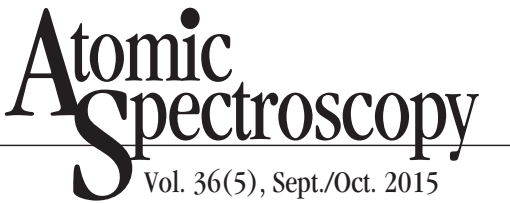

\section{RESULTS AND DISCUSSION}

Various standard digestion methods $(20,28-30)$ have been reported in the literature for the analysis of soil and sediment samples for their metallic constituents. Different combinations of acids $\left(\mathrm{HNO}_{3}, \mathrm{HF}\right.$, $\mathrm{HCl}$, etc.) have been suggested for the digestion or extraction of the trace elements in the soil. All of these methods are based on strong acid digestions. In USEPA Method 3050B (30), the soil/sediment is digested with repeated additions of nitric acid and hydrogen peroxide, followed by addition of hydrochloric acid, while in the ISO 11466 method (20), the sample is predigested overnight in an $\mathrm{HCl}-\mathrm{HNO}_{3}$ mixture (aqua regia) and then heated, followed by dilution with $\mathrm{HNO}_{3}$. These procedures, however, are not total digestion techniques as the elements associated with silicates remain undissolved. The use of $\mathrm{HF}$ becomes unavoidable to extract such metal ions. Similarly, the total digestion method of US EPA 3052 (29) employed herein for validation purposes also requires a mixture of concentrated $\mathrm{HNO}_{3}$ and HF.

However, the use of concentrated acids, especially HF, complicates the subsequent analysis where ICP techniques (AES/OES or MS), two of the most sensitive and rapid analytical techniques, are employed for the analysis of metallic constituents. In addition, the use of large volumes of concentrated acids can also lead to higher process blanks, affecting the sensitivities achieved. Unlike these methods, the method proposed herein achieves almost complete digestion (with very little traces of silica) using a mixture of dilute $\mathrm{HNO}_{3}$ and $\mathrm{HF}$, employing a closed microwave digestion technique to prevent any possible loss of analytes, and is especially suitable for ICP analysis. 


\section{Method Validation}

The Chinese certified reference material GBW-07409 Soil was analyzed by the developed method, followed by soil samples from Tummalapalle, Andhra Pradesh, India. The concentrations of 18 trace elements were determined in both samples and are reported in Tables III and IV. The standard US EPA 3052 method was used for comparison purposes with the proposed digestion procedure. As may be seen from these results, there is excellent agreement of the results. Applying the Student's $t$-test and comparing the certified values of GBW-07409 Soil with the mean value obtained by the proposed method showed good agreement at the 95\% confidence level. In addition, by applying the pairedcomparison $t$-test with multiple samples (18 elements) showed that the results of the two independent methods for both soil samples (GBW-07409 and soil from Tummalapalle) did not differ significantly at the $95 \%$ confidence level. The pvalues obtained for GBW-07409 Soil and Tummalapalle soil were 0.25 and 0.50 , respectively. As shown in Tables III, the recoveries obtained by the developed method range from $86 \%$ to $104 \%$, which is quite similar to those obtained by the US EPA 3052 method for the GBW 07409 reference sample.

\section{Effect of HF Concentration}

An acid mixture of $10 \mathrm{~mL}$ containing different concentrations of $\mathrm{HNO}_{3}$ and $\mathrm{HF}$ was used during optimization, the use of HF being essential to completely break the complex silicate matrix to extract the trace elements. The closed microwave digestion program used is given in Table II. Initially, the digestion was performed using $10 \%$ (v/v) $\mathrm{HNO}_{3}$ without adding $\mathrm{HF}$. Then the effect of increasing the concentration of HF to $2 \%$ (v/v), 5\% (v/v), 7\% (v/v), and 10\% $(\mathrm{v} / \mathrm{v})$ was investigated. The use of
TABLE III

Concentration Values Obtained for GBW-07409 (in $\mathrm{mg} \mathrm{kg}^{-1}$ )

\begin{tabular}{|c|c|c|c|c|c|}
\hline \multirow[t]{2}{*}{ Elements } & \multirow{2}{*}{$\begin{array}{l}\text { Certified } \\
\text { Concen- } \\
\text { tration }\end{array}$} & \multicolumn{2}{|c|}{ US EPA 3052} & \multicolumn{2}{|c|}{ Present Method } \\
\hline & & $\begin{array}{l}\text { Conc. } \pm- \\
\text { s.d. }\end{array}$ & $\begin{array}{c}(\%) \\
\text { Recovery }\end{array}$ & $\begin{array}{l}\text { Conc. } \pm \\
\text { s.d. }^{\mathrm{a}}\end{array}$ & $\begin{array}{c}(\%) \\
\text { Recovery }\end{array}$ \\
\hline $\mathrm{Li}$ & 14.3 & $12.2 \pm 0.6$ & 85 & $13.1 \pm 0.8$ & 92 \\
\hline $\mathrm{Be}$ & 2.1 & $2.2 \pm 0.1$ & 104 & $2.0 \pm 0.2$ & 96 \\
\hline V & 34.7 & $37.1 \pm 0.9$ & 107 & $35.1 \pm 0.7$ & 101 \\
\hline $\mathrm{Cr}$ & 26.4 & $27.1 \pm 1.1$ & 103 & $24.4 \pm 1.0$ & 92 \\
\hline Co & 4.9 & $5.1 \pm 0.3$ & 104 & $5.0 \pm 0.2$ & 102 \\
\hline $\mathrm{Ni}$ & 9.3 & $9.8 \pm 0.3$ & 105 & $9.7 \pm 0.2$ & 104 \\
\hline $\mathrm{Cu}$ & 4.9 & $5.2 \pm 0.4$ & 106 & $5.0 \pm 0.3$ & 103 \\
\hline $\mathrm{Zn}$ & 34.2 & $36.0 \pm 1.1$ & 105 & $33.3 \pm 0.5$ & 97 \\
\hline $\mathrm{Ga}$ & 14.6 & $14.8 \pm 0.2$ & 102 & $15.2 \pm 0.2$ & 104 \\
\hline As & 2.9 & $3.1 \pm 0.2$ & 107 & $3.0 \pm 0.1$ & 103 \\
\hline $\mathrm{Sr}$ & 270 & $246 \pm 20$ & 91 & $247 \pm 14$ & 91 \\
\hline Mo & 0.43 & $0.41 \pm 0.02$ & 95 & $0.38 \pm 0.02$ & 88 \\
\hline Sn & 1.4 & $1.5 \pm 0.1$ & 107 & $1.3 \pm 0.1$ & 93 \\
\hline $\mathrm{Ba}$ & 693 & $681 \pm 30$ & 98 & $638 \pm 25$ & 92 \\
\hline $\mathrm{Tl}$ & 0.58 & $0.6 \pm 0.1$ & 103 & $0.5 \pm 0.1$ & 94 \\
\hline $\mathrm{Pb}$ & 16.3 & $15.3 \pm 0.4$ & 94 & $15.8 \pm 0.3$ & 97 \\
\hline $\mathrm{Bi}$ & 0.1 & $0.1 \pm 0.02$ & 100 & $0.1 \pm 0.03$ & 89 \\
\hline $\mathrm{U}$ & 1.6 & $1.5 \pm 0.1$ & 94 & $1.4 \pm 0.1$ & 86 \\
\hline
\end{tabular}

${ }^{\mathrm{a}}$ s.d. $=$ standard deviation of $\mathrm{n}=3$ replicates

TABLE IV

Concentration Values Obtained for Tummalapalle Soil (in mg kg-1)

\begin{tabular}{lccc}
\hline Elements & $\begin{array}{c}\text { US EPA 3052 } \\
\text { Conc. } \pm \text { s.d. }\end{array}$ & $\begin{array}{c}\text { Present Method } \\
\text { Conc. } \pm \text { s.d. }\end{array}$ & $\begin{array}{c}\text { Relative (\%) } \\
\text { Difference }\end{array}$ \\
\hline $\mathrm{Li}$ & $23.6 \pm 1.0$ & $25.1 \pm 0.4$ & 6.4 \\
$\mathrm{Be}$ & $1.7 \pm 0.1$ & $1.8 \pm 0.1$ & 5.9 \\
$\mathrm{~V}$ & $131 \pm 4$ & $137 \pm 3.0$ & 4.6 \\
$\mathrm{Cr}$ & $92.5 \pm 2.5$ & $93.8 \pm 2.0$ & 1.4 \\
$\mathrm{Co}$ & $22.5 \pm 1.0$ & $23.8 \pm 0.5$ & 5.8 \\
$\mathrm{Ni}$ & $60.7 \pm 2.1$ & $63.4 \pm 1.0$ & 4.4 \\
$\mathrm{Cu}$ & $68.6 \pm 2.7$ & $72.5 \pm 1.3$ & 5.7 \\
$\mathrm{Zn}$ & $45.1 \pm 3.0$ & $42.1 \pm 1.2$ & 6.6 \\
$\mathrm{Ga}$ & $13.1 \pm 1.0$ & $13.5 \pm 0.3$ & 3.0 \\
$\mathrm{As}$ & $17.8 \pm 1.4$ & $18.0 \pm 1.0$ & 1.1 \\
$\mathrm{Sr}$ & $52.3 \pm 2.1$ & $53.2 \pm 1.5$ & 1.7 \\
$\mathrm{Mo}$ & $2.4 \pm 0.2$ & $2.3 \pm 0.1$ & 4.2 \\
$\mathrm{Sn}$ & $1.6 \pm 0.1$ & $1.5 \pm 0.1$ & 6.2 \\
$\mathrm{Ba}$ & $692 \pm 58$ & $621 \pm 43$ & 10.3 \\
$\mathrm{Tl}$ & $0.5 \pm 0.1$ & $0.4 \pm 0.1$ & 20.0 \\
$\mathrm{~Pb}$ & $12.1 \pm 1.2$ & $10.9 \pm 0.5$ & 9.9 \\
$\mathrm{Bi}$ & $0.4 \pm 0.1$ & $0.4 \pm 0.1$ & 5.1 \\
$\mathrm{U}$ & $4.5 \pm 0.1$ & $4.2 \pm 0.1$ & 6.7 \\
\hline $\mathrm{S}$ & & &
\end{tabular}

${ }^{\mathrm{a}}$ s.d. $=$ standard deviation of $\mathrm{n}=3$ replicates. 


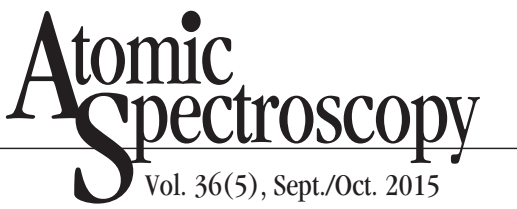

$10 \%(\mathrm{v} / \mathrm{v}) \mathrm{HNO}_{3}+7 \%(\mathrm{v} / \mathrm{v}) \mathrm{HF}$ acid mixture gave quantitative recoveries (86-107\%) for the highest number of elements (18 elements) as listed in Tables III and IV. Increasing the concentration of HF beyond $7 \%$ did not show any further improvement in recoveries. The use of $10 \mathrm{~mL}$ of a mixture of $10 \%$ (v/v) $\mathrm{HNO}_{3}+7 \%$ (v/v) $\mathrm{HF}$ for approximately $0.3 \mathrm{~g}$ sample resulted in almost complete digestion, with minor traces of silica, which did not affect the recovery of the trace elements. This was apparently based on the fact that addition of further HF did not yield any improvement in the recoveries.

\section{Removal of HF for Analysis by ICP-MS}

The digested solution containing close to $10 \%$ (v/v) $\mathrm{HNO}_{3}$ and $7 \%$ (v/v) HF could not be passed directly into the ICP-MS for analysis as the high concentration of $\mathrm{HF}$ is detrimental to the glassware used in the sample introduction system. But any dilution of the sample could result in the level of the analytes falling below the detection limits. Thus, for both digestion methods, an aliquot of the digested solution was evaporated over an IR lamp to incipient dryness until white residue was seen at the bottom of the container. The residue was treated with $600 \mu \mathrm{L}$ of $\mathrm{HNO}_{3}$, $200 \mu \mathrm{L}$ of $\mathrm{HCl}$, and $1 \mathrm{~mL}$ of ultrapure water and warmed for a few minutes over the IR lamp, cooled, and made up to a known volume with ultrapure water to get a clear solution. $\mathrm{HCl}$ was added to stabilize elements such as $\mathrm{Sn}, \mathrm{Ba}$, etc. To check for any loss of analyte by volatilization while removing the HF, a known amount of multielement standard was spiked at two different concentration levels (0.5 and $1.0 \mu \mathrm{g}$ absolute) to the digested solution, before evaporating over the IR lamp. The \% recovery of all of the elements reported was between 90 to $100 \%$. Even for volatile elements like arsenic, the \% recovery was quantitative.

\section{Analytical Characteristics}

The analytical characteristics of the target elements were studied using the optimized microwave digestion procedure with dilute acids. The limits of detection (LOD) calculated based on three times the standard deviation of the process blank $(n=6)$ for both methods are listed in Table V. The detection limits obtained, as can be seen, by the present method showed an improvement by an order of magnitude for elements $\mathrm{Cr}, \mathrm{Cu}, \mathrm{Zn}$, As, Sr, and $\mathrm{U}$ when compared to the US EPA 3052 method, possibly due to better signal stability obtained by using dilute acids. For the rest of the elements, the detection limits were similar.

The reproducibility of the proposed method was obtained by digesting the CRM GBW- 07409 Soil in duplicate on 6 different days and then analyzing it. The RSD values obtained for the 18 elements were lower than $10 \%$, except for $\mathrm{Tl}$ and $\mathrm{Bi}$, which were found to be present at very low concentrations in the analyzed soil samples. The process blank values calculated with respect to sample weight for both digestion methods are listed in Table VI. Although both digestion methods were performed under closed microwave conditions, the process blank values, as shown in Table VI, are higher for the US EPA 3052 method compared to the proposed method for most of the elements. Thus, the advantages of the proposed method are low process blank values, determination of 18 elements in a single analysis, and the ability to obtain exhaustive chemical information in the shortest time possible. Most of the methods reported in the literature have often focused on determining fewer elements, Cd, Co, Cr, Cu, $\mathrm{Mn}, \mathrm{Ni}, \mathrm{Pb}$, and $\mathrm{Zn}$ in soil using
TABLE V Limit of Detection $(n=6)$

\begin{tabular}{ccl}
\hline $\begin{array}{c}\text { Ele- } \\
\text { ment }\end{array}$ & $\begin{array}{c}\text { US EPA } \\
3052 \\
\left(\mathrm{mg} \mathrm{kg}^{-1}\right)\end{array}$ & $\begin{array}{c}\text { Present } \\
\text { Method } \\
\left(\mathrm{mg} \mathrm{kg}^{-1}\right)\end{array}$ \\
\hline $\mathrm{Li}$ & 0.003 & 0.003 \\
$\mathrm{Be}$ & 0.003 & 0.004 \\
$\mathrm{~V}$ & 0.002 & 0.001 \\
$\mathrm{Cr}$ & 0.03 & 0.008 \\
$\mathrm{Co}$ & 0.001 & 0.003 \\
$\mathrm{Ni}$ & 0.015 & 0.015 \\
$\mathrm{Cu}$ & 0.2 & 0.004 \\
$\mathrm{Zn}$ & 0.1 & 0.02 \\
$\mathrm{Ga}$ & 0.006 & 0.003 \\
$\mathrm{As}$ & 0.2 & 0.04 \\
$\mathrm{Sr}$ & 0.06 & 0.007 \\
$\mathrm{Mo}$ & 0.004 & 0.001 \\
$\mathrm{Sn}$ & 0.02 & 0.008 \\
$\mathrm{Ba}$ & 0.008 & 0.004 \\
$\mathrm{Tl}$ & 0.003 & 0.001 \\
$\mathrm{~Pb}$ & 0.036 & 0.007 \\
$\mathrm{Bi}$ & 0.013 & 0.003 \\
$\mathrm{U}$ & 0.030 & 0.003 \\
\hline & & \\
\hline
\end{tabular}

TABLE VI Process Blank Values $(n=6)$

\begin{tabular}{ccc}
\hline $\begin{array}{c}\text { Ele- } \\
\text { ment }\end{array}$ & $\begin{array}{c}\text { US EPA } \\
3052 \\
\left(\mathrm{mg} \mathrm{kg}^{-1}\right)\end{array}$ & $\begin{array}{c}\text { Present } \\
\text { Method } \\
\left(\mathrm{mg} \mathrm{kg}^{-1}\right)\end{array}$ \\
\hline $\mathrm{Li}$ & 0.01 & 0.01 \\
$\mathrm{Be}$ & 0.03 & 0.002 \\
$\mathrm{~V}$ & 0.04 & 0.02 \\
$\mathrm{Cr}$ & 0.32 & 0.18 \\
$\mathrm{Co}$ & 0.01 & 0.004 \\
$\mathrm{Ni}$ & 0.4 & 0.2 \\
$\mathrm{Cu}$ & 3.7 & 0.3 \\
$\mathrm{Zn}$ & 1.6 & 0.3 \\
$\mathrm{Ga}$ & 0.01 & 0.01 \\
$\mathrm{As}$ & 2.30 & 0.15 \\
$\mathrm{Sr}$ & 0.03 & 0.02 \\
$\mathrm{Mo}$ & 0.01 & 0.01 \\
$\mathrm{Sn}$ & 0.2 & 0.1 \\
$\mathrm{Ba}$ & 0.15 & 0.04 \\
$\mathrm{Tl}$ & 0.004 & 0.003 \\
$\mathrm{~Pb}$ & 0.3 & 0.06 \\
$\mathrm{Bi}$ & 0.06 & 0.01 \\
$\mathrm{U}$ & 0.008 & 0.007 \\
\hline & & \\
& &
\end{tabular}


concentrated acids. The concentrations of the trace elements reported for the soil samples in Tables III and IV are corrected for moisture content of the samples.

\section{Analysis of Real Soil Sample}

The Uranium Corporation of India Limited (UCIL) established a uranium mining and milling facility at Tummalapalle, YSR Kadapa district, Andhra Pradesh state, India, to meet the energy security for the nation. To ensure that the uranium mining activity does not significantly influence the existing environmental quality in and around the villages during extraction, it is essential to establish a preliminary survey of the elemental contents of soil and other parameters in and around the site to generate extensive baseline data. A finely powdered soil sample was digested by the developed method and compared with the standard US EPA 3052 method for its trace elemental content. The results in Table IV show that the two methods are in good agreement. The concentration of uranium and other elements are at slightly elevated levels. The use of fertilizers and pesticides over a long period of time might have led to the accumulation of these trace elements in the soil collected from agricultural land. Our laboratory is in the process of making a soil reference material. The results show that this soil sample could be a suitable candidate for preparing a soil reference material with trace elements at high levels.

\section{CONCLUSION}

An environmently friendly method for the total digestion of the soil samples, followed by determination of 18 elements ( $\mathrm{Li}, \mathrm{Be}, \mathrm{V}$, Cr, Co, Ni, Cu, Zn, Ga, As, Sr, Mo, $\mathrm{Sn}, \mathrm{Ba}, \mathrm{Tl}, \mathrm{Pb}, \mathrm{Bi}$, and $\mathrm{U}$ ) has been reported. The total digestion of soil was achieved using dilute acids $\left[10 \%(v / v) \mathrm{HNO}_{3}+7 \%(\mathrm{v} / \mathrm{v}) \mathrm{HF}\right]$ unlike many total digestion methods that often employ mixtures of concentrated acids using closed microwave digestion. The present method allows a large number of metal constituents to be determined quantitatively, requires shorter digestion times, and offers good recoveries for the volatile elements. In addition, the use of dilute acids has resulted in low process blank values with better detection limits (0.001 to $0.04 \mathrm{mg} \mathrm{kg}^{-1}$ ). The high reproducibility of the method shows that it can be routinely used for the determination trace elements in soil.

\section{ACKNOWLEDGMENT}

The authors wish to acknowledge constant support and encouragement from Dr. Sunil Jai Kumar, Head, N.C.C.C.M., B.A.R.C.

Received February 25, 2015

\section{REFERENCES}

1. J. Aguilar, C. Dorronsoro, E. Fernández, J. Fernández, I. García, F. Martín and M. Simón, Environ. Pollut. 132, 395 (2004).

2. C.N. Mulligan, R.N. Yong and B.F. Gibbs, Eng. Geol. 60, 193 (2001).

3. B. Marin, E.I.B. Chopin, B. Jupinet and D. Gauthier, Talanta 77, 282 2008).

4. B.J. Alloway, Heavy Metals in Soils, Blackie Academic \& Professional, London, U.K., pg. 368 (1995).

5. S. Melaku, R. Dams and L. Moens, Anal. Chim. Acta 543, 117 (2005).

6. A. Väisänen and A. Ilander, Anal. Chim. Acta 570, 93 (2006).

7. B. Palumbo, M. Angelone, A. Bellanca, C. Dazzi, S. Hauser, R. Neri and J. Wilson, Geoderma 95, 247 (2000).

8. V. Salonen and K. K. Niemi, Appl. Geochem. 22, 906 (2007).

9. F.A. Nicholson, S.R. Smith, B.J. Alloway, C. Carlton-Smith and B.J. Chambers, Sci. Total Environ. 311, 205 (2003).
10. A. Tessier, P. G. C. Campbell and M. Bisson, Anal. Chem. 51, 844 (1979).

11. M. Pueyo, J. Mateu, A. Rigol, M. Vidal, J.F. López-Sánchez and G. Rauret, Environ. Pollut. 152, 330 (2008).

12. C. Gleyzes, S. Tellier and M. Astruc, TrAC Trend Anal. Chem. 21, 451 (2002).

13. Q. M. Jaradat, A.M. Massadeh, M.A. Zaitoun and B.M. Maitah, Environ. Monit. Assess. 112, 197 (2006).

14. E. Konradi, T. Frentiu, M. Ponta and E. Cordos, Acta Universitatis Cibiniensis Seria F Chemia 8, 5 (2005).

15. B. Marin, E.I.B. Chopin, B. Jupinet and D. Gauthier, Talanta 77, 282 2008).

16. V. Sandroni, C.M.M. Smith and A. Donovan, Talanta 60, 715 (2003).

17. S. Melaku, I. Gelaude, F. Vanhaecke, L. Moens and R. Dams, Microchim. Acta, 142, 7 (2003).

18. A. Väisänen and A. Ilander, Anal. Chim. Acta 570, 93 (2006).

19. H. M. Kingston and L.B. Jassie, Introduction to Microwave Sample Preparation: Theory and Practice, American Chemical Society (1988).

20. ISO, Soil Quality, Extraction of Trace Elements Soluble in Aqua Regia, ISO 11466 (1995).

21. J. Sastre, A. Sahuquillo, M.Vidal and G. Rauret, Anal. Chim. Acta 462, 59 (2002).

22. Z. Mester, M. Angelone, C. Brunori, C. Cremisini, H. Muntau and R. Morabito, Anal. Chim. Acta 395, 157 (1999).

23. R. Falciani, E. Novaro, M. Marchesini and M. Gucciard, J. Anal. At. Spectrom. 15, 561 (2000).

24. S. P. Santana, M. P. Alfonso, M. V. Tagle, M. Peña Icart, C. Brunori and R. Morabito, Chemosphere 66, 1545 (2007).

25. B. Wei and L. Yang, Microchem. J. 94, 99 (2010).

26. M. A. Wilson, R. Burt and C. W Lee, Commun. Soil Sci. Plan. 37, 513 (2006). 


\section{A $_{\text {Spectroscopy }}^{\text {tomic }}$ \\ 1 Vol. 36(5), Sept./Oct. 2015}

27. D. McGrath, Talanta 46, 439 (1998).

28. EPA Method 3052, Microwaveassisted acid digestion of siliceous and organically based matrices, U.S. Environmental Protection Agency, pp. 1-20 (1996).

29. EPA Method 3050B, Acid digestion of sediments, sludges and soils, U.S. Environmental Protection Agency, pp. 1-12 (1996).

30. EPA Method 3051a, Microwaveassisted acid digestion of sediments, sludges, soils, and oils, U.S. Environmental Protection Agency, pp. 1-30 (2007). 